\title{
Memoria y traición femenina en la ficción y el testimonio.
}

(La doble vida de Arturo Fontaine, El fin de la historia de Liliana Heker y testimonios de sobrevivientes)

Memory and femenine betrayal in fiction and testimony

\section{BERNARDITA LLANOS}

BROOKLYN COLLEGE, CUNY · bllanos@brooklyn.cuny.edu

Profesora en Brooklyn College de CUNY, es autora de numerosos artículo sobre género, cultura y violencia. Ha publicado los libros Letras y proclamas: la estética literaria de Diamela Eltit, Passionate Subjects/Split Subjects in Twentieth Century Luterature in Chile. Brunet, Bombal and Eltit, junto a Ana María Goestchel, Fronteras de la memoria: cartografías de género en artes visuales, cine y literatura, en la Américas y en España.

Resumen: El artículo analiza la representación de las mujeres que, habiendo formado parte de la militancia de izquierda en los setenta, pasó a colaborar con los organismos represivos después de haber sido sometidas a una tortura extrema. Algunas novelas contemporáneas, como La vida doble o El fin de la historia construyen su relato en torno a estas figuras, que catalogan bajo el paradigma de la traición, contribuyendo a la consolidación de narrativas estigmatizadoras en torno a ellas.

Palabras clave: Represión, traición, género, testimonio, ficción.
Resumen: The article focuses on the representation of women who were leftist militants in the seventies but became collaborators of the repressive institutions, after suffering an extreme violence against them. Some contemporary novels, such as $L a$ vida doble or El fin de la historia fictionalize the life of some of these women. The article focuses in the way they do it and the meanings the contribute to build about political militance, repression and betrayal.

Palabras clave: Repression, Betrayal, Gender, Testimony, Fiction. 
Mucho se ha escrito sobre el testimonio y las formas en que ha alterado la institución literaria y en especial los diversos géneros y narrativas del yo, desde la ficción hasta la propia ley y la historia han visto los efectos de las enunciaciones de un yo desautorizado que logra desequilibrar las estructuras de las meta-narrativas nacionales hegemónicas. El gran aporte del testimonio se ha dado en el campo de la subjetividad configurando relatos que, como René Jara afirmaba acertadamente en los ochenta, eran “en su significación más elemental y básica, [son] la historia que continua” y "una manera diferente de vivir el ahora" (Prólogo:1982: 3). Para René Jara como para otros críticos y pensadores que han continuado la discusión desde otras ópticas y perspectivas culturales en las décadas siguientes, la palabra testimonial aparece comprometida en "la realidad del objeto que muestra y acusa" (2) fundando un sujeto singular, quien vivo textualiza lo que ha sido su paso por la muerte, al decir de Jara. Desde una óptica feminista esta suerte de sobrevivencia a una experiencia liminal marcada por el género y una memoria sexuada, le da una fuerza y potencia política inédita al sujeto testimonial femenino, cuya experiencia se constituye por la vulnerabilidad del cuerpo en situación de tortura sexual. En el contexto del encarcelamiento ilegal y la tortura sexual al interior de los centros clandestinos, no existe la posibilidad del consentimiento de la víctima pues la naturaleza de la represión dictatorial y la situación de violencia extrema que la define, hace de la sumisión y la obediencia femenina las formas predominantes de sobrevivencia no solo en el cautiverio sino también en otras instituciones patriarcales rearticuladas por la violencia sistemática del régimen policial. Como afirma Debra Bergoffen, la vulnerabilidad humana consiste en la humillación y el trauma, los cuales también se manifiestan en las realidades imaginarias y simbólicas a través de las cuales encarnamos nuestra corporalidad (2012: 74). En los relatos testimoniales y de memorias de sobrevivencia de mujeres cautivas durante las dictaduras del Cono Sur encontramos el cuerpo vulnerable y sexuado de la víctima, en situación de acoso y vejamen y donde el consentimiento de la sujeto se constituye dentro del abuso sistemático (verbal, físico y psicológico) mediante tácticas del terror. En este contexto de arrasamiento sistematizado, la tortura sexual funciona como una de las formas de violación cuyo objetivo es vaciar la subjetividad de la víctima para reorganizarla con otros contenidos afines con la ideología represiva.

Dentro de los nuevos avances en materia de DDHH. el sujeto vulnerable propio del escenario bélico y violento, ha sido definido desafiando la concepción tradicional del sujeto político autónomo del discurso liberal y su contrato sexual. A la mujer en tanto víctima de la violencia y tortura sexual se le reconoce el derecho a la determinación sexual, un derecho humano a la par de la igualdad y la libertad. Paralelamente se le otorga dignidad al cuerpo vulnerable lo que es un avance inédito que se logra a partir de los veredictos de los tribunales de las cortes internacionales contra las violaciones sexuales genocidas productos de las guerras étnicas de la antigua Yugoslavia. 
En este nuevo paradigma de los Derechos Humanos la experiencia del sujeto vulnerable se encarna en el cuerpo, depositario y portador de los traumas y debilidades ha que ha sido sometido por la impunidad del poder. Esta nueva categoría nos permite acercarnos a los testimonios y representaciones de las mujeres combatientes desde una nueva óptica que nos permite entender la tortura sexual como un derecho humano básico ligado a la determinación y libertad sexual que les fue arrebatada, reduciéndolas a la vulnerabilidad extrema en los centros de detención ilegales creados por las dictaduras militares. Estas memorias, por lo tanto, abren la discusión a las marcas sexuadas de las sobrevivientes y el impacto que la violación de los Derechos Humanos tuvo en el contexto dictatorial.

Las diversas modalidades y géneros de la memoria de las dictaduras argentinas y chilenas se han revisado, reescrito y filmado en un sin número de autobiografías, testimonios, novelas y documentales desde los años 80 hasta hoy en día. Como subraya Leonor Arfuch en su libro Crítica cultural entre política y poética (2008) desde hace más de tres décadas la memoria ha sido objeto de indagación, tematización y reflexión teórica y ha atravesado diversas etapas, polémicas y confrontaciones (2008: 161). La memoria traumática también es parte del horizonte internacional desde la Shoa y hoy en día se torna una memoria viva en sociedades pos dictatoriales y en aquellas que enfrentan una suerte de "guerra perpetua" o el "estado de excepción" del que habla Agamben vuelto sistema cotidiano (Arfuch, 2008: 162). Desde las historias heroicas de guerrilleros caídos en la lucha hasta los desaparecidos, cuyos cadáveres aún permanecen insepultos a los reclamos de la segunda y hasta tercera generación por la ausencia de padres o abuelos, los relatos tienen la historia de la dictadura y sus abusos marcados en la propia identidad de quien narra. Dentro de este amplio archivo memorialístico los relatos de sobrevivientes que fueron prisioneros políticos forman una categoría especial ya que sus historias están signadas por el trauma de la tortura propia y ajena, la indefensión extrema y el sometimiento al cautiverio.

Entre las memorias más abyectas de sobrevivientes se encuentran las de las mujeres que se quebraron, aquellas que no soportaron el dolor y el terror a la muerte o la amenaza de perder a un ser querido y hablaron, delataron y colaboraron. Bajo condiciones de terror y castigo sistemático solo la voluntad de sobrevivir las mantiene con vida al borde del instinto y en una progresiva transformación identitaria. El cambio que sufren las colaboradoras se da paralelamente a la cercanía con un torturador o un agente de la policía secreta que se ve como el detentor de la propia salvación, dueño de otorgar la vida y la muerte en un mundo de "muertos vivos" como los llamará Marcia Alejandra Merino en el documental 
de Carmen Castillo, La Flaca Alejandra (1994). ${ }^{1}$ Pertenecientes en su mayoría a grupos revolucionarios militarizados, las ex militantes rompen con el código moral del grupo al que se afilian y destruyen el principio de lealtad a sus compañeros militantes.

En estas narraciones se encuentran ex montoneros argentinos y ex miristas chilenos y entre sus personajes principales pasan al campo literario la ex montonera Leonora Ordaz de la novela El fin de la historia (1996) de la argentina Liliana Heker y la ex militante de Hacha Roja, Lorena (otras veces llamada Irene como nombre de guerra), personaje central de La vida doble (2010) del chileno Arturo Fontaine. Ambas militantes se vuelven delatoras, colaboradoras e interrogadoras y hasta torturadoras (en el caso de Lorena) para el aparato represivo tal como lo fueron en la realidad Marcia Alejandra Merino y Luz Arce, quienes relatan sus experiencias de tortura y vejación sexual como de colaboración en las autobiografías Mi verdad. Más allá del horror, yo acuso (1994) de Merino y El infierno (1993) de Arce, respectivamente. Lo que estos relatos tienen en común con las novelas que analizo aquí es el binario de la sobreviviente/traidora junto a la presencia del militar captor que "deviene amante o socio (en la carrera política dentro de la institución militar que emprenden las otrora militantes” como afirma Ana Longoni (2007: 139).

Las novelas, sin embargo, utilizan el discurso testimonial y sus tópicos para crear un pacto de lectura que irremediablemente condena a la sobreviviente moralmente mediante diversos dispositivos tales como la propia autoconfesión (La vida doble) o el juicio moral del narrador (El fin de la historia). Jaume Peris Blanes sostiene acertadamente que la despolitización que transparenta la representación de la militancia y la colaboración en La vida doble presenta una reflexión problemática y cuestionable sobre la violencia política y militar homologándola a otras formas de violencia (2010: 57). Al interpretar la violencia de este modo - tanto dictatorial como militante-, la política y la historia social se vuelven irrelevantes, pues de lo que se trata es de una suerte de fuerza irracional que irrumpe no solo en los individuos sino en la sociedad en su conjunto. Como resalta Peris Blanes la violencia se torna parte de una pulsión sexual tal como la representa Fontaine en su personaje/informante/colaboradora dentro de una atmósfera difusa (2010: 57-58).

La literatura, como advierte Longoni, y concuerdo con su afirmación, tiende a propagar también un paradigma binario y militarista de los organizaciones armadas y "la naturalización del binomio héroetraidor" propio de la épica y la guerra (2007: 133). Esta lógica de guerra obturó la posibilidad en la izquierda más radical de comprender la política en otros términos que no fueran los del paradigma militar

1 Ver mis artículos “La espacialización de la memoria en Nona Fernández y Carmen Castillo." Chile Urbano. Ed. Magda Sepúlveda. Santiago: Universidad Católica de Chile/Cuarto Propio, 2013. 131-147 y "Memoria, afectos y géneros en documentales chilenos y argentinos". Revista de Historia. No7 (Primer Semestre, 2012): 93-102. 
de morir o vencer. Dentro de este marco, los sobrevivientes solo caben como traidores (Longoni, 2007: 123). Lo que es evidente es que la tortura fue una modalidad efectiva y atroz de desmantelar rápidamente la estructura de las organizaciones armadas como afirma Longoni (2007: 121).

Desempeñarse como interrogadora, analista de inteligencia, espía en misiones y operativos de alto riesgo nacional e internacional son algunos de los nuevos roles de estas mujeres en la estructura de poder del aparato represivo. La organización jerárquica y de mando en el campo de concentración intenta involucrar a ex militantes y militares creando diversos grupos de staff (Leonora participa en uno) o ministaffs de inteligencia, donde se va colocando a los prisioneros colaboradores como parte del proyecto de reeducación y recuperación (Longoni 105). Sin embargo, no debe pasarse por alto, como lo hacen estas novelas, que el estado de víctima de los detenidos, implica que nada de lo que hacen es por libre voluntad y que para ellos la sobrevida está determinada por el peligro inminente de la muerte y la tortura. De ahí el doble vínculo con sus captores, quienes aparecen como todopoderosos y las únicas autoridades que pueden salvarlas o condenarlas a muerte.

El aislamiento, el miedo y la dependencia de los captores vendrían a convertirse en las condiciones que posibilitan el desarrollo de esta corriente afectiva con sus verdugos más allá del abuso y tortura sexual cotidiana ejercida sobre las mujeres detenidas en las cárceles clandestinas, como lo examina la antropóloga Ximena Bunster para las dictaduras latinoamericanas. Dentro de las diversas experiencias que se narran sobre ex combatientes transformadas en colaboradoras o eficientes agentes de los servicios de inteligencia, sin embargo, la maternidad y la identidad de madre se erigen como los únicos roles que persisten en una subjetividad arrasada por la disociación, el trauma y el miedo (a ser reconocida o asesinada por antiguos compañeros militantes entre otros). Por esta razón el exilio al final de las novelas, ilustra la necesidad de irse del país de origen (Chile y Argentina) para vivir la nueva identidad y vida lejos, donde no las reconozcan (igual como lo hiciera Marcia Alejandra Merino). En este sentido habría paralelos entre la representación literaria y la testimonial ya que es la vuelta a los roles femeninos más convencionales lo que también pone en jaque los valores revolucionarios. Proteger a la hija viene a ser un deseo fundamental de quienes tuvieron que olvidarse de todo lo que representaba la feminidad, los vínculos de pareja y la familia burguesa de la que provenían y convertirse en la "mujer nueva" al entrar a la militancia revolucionaria más aún si eran combatientes.

La novela de Arturo Fontaine La vida doble es una suerte de testimonio confesión de una ex combatiente del grupo revolucionario Hacha Roja vuelta colaboradora de la dictadura que le cuenta su vida a un escritor ficticio por una alta suma de dinero. Se ha dicho que está inspirada libremente en la vida de Marcia Alejandra Merino, alta dirigente del MIR, quien traiciona a sus compañeros llevándolos a la muerte. También el autor afirma que su protagonista es una suerte de avatar creada a partir de entrevistas que él hizo o leyó de ex combatientes de izquierda. De hecho la novela integra las formas 
retóricas de estos testimonios y los tópicos y desafíos de las ex revolucionarias, a la vez que cuestiona sus opciones de vida y el proyecto político al que pertenecían a través de la confesión de la propia protagonista en un sutil pacto de lectura. Lorena vive aún exiliada en Estocolmo, tiene cáncer terminal y acepta entregarle su testimonio al autor ficticio por dinero que le dejará a su hija. La amargura, el desencantado y la enfermedad son condiciones que determinan a la protagonista en el presente. Su proceso de contar y recordar cómo cayó presa después de un atentado fallido a una casa de cambio en Santiago. Así inicia su vida en cautiverio, aislada y torturada por 29 días para ser dejada libre provisionalmente. Pronto vuelve a ser detenida y llevada al centro de clandestino con la certidumbre de no poder tolerar la tortura y la amenaza de que secuestren a su hija. La degradación absoluta también es parte de la novela, pues Lorena se va progresivamente internando en la policía secreta a través de su colaboración hasta que muere su identidad previa y renace otro yo:

Así empecé a colaborar y colaborar será delatar a los hermanos, darle-contrita sus nombres a tu confesor, al Flaco o al Gato... Hay un vértigo en la delación. Literalmente uno se da vuelta. Y confiesa y llora y cuenta y llora nombres, fechas, lugares marchitos. Y al hacerlo desaparece el miedo al dolor desaparece y, por un instante, se reconcilia uno con ese Dios terrible que exigió la inmolación (Fontaine, 2010: 155).

Cuando poco después Irene vuelve a ser detenida da un inesperado vuelco, y todo comienza a confundirse y a pervertirse de forma cruel y peligrosa en el submundo de la policía secreta donde colabora estando presa, saliendo de noche con uno de sus captores a bailar, beber y participar en orgías. En ella la colaboración y la tortura se realizan por su hija, pero también, porque con el tiempo encuentra placer en el juego sadomasoquista del poder según la lógica narrativa. Como única explicación de su primera traición a Carmelo, su compañero combatiente caído el día del asalto, dice: "Quise sobrevivir. Quise una prórroga" como una forma de rebelarse frente a la muerte y al peligro que enfrentaba. Con el tiempo y encargada de diversos operativos tanto en Chile como en Europa, fracturándose entre la disociación y el distanciamiento como revela su relato en el presente: “Tú no comprendes a esta Lorena que escuchas: yo bebo el cáliz de mi propia abyección. Es dulce y amargo mi cáliz como un vicio. Un largo resentimiento puede proteger y sostener". Así, representa Fontaine a la ex guerrillera vuelta colaboradora, como alguien cuya propia personalidad se ha trastocado y pervertido por la impunidad excepto en su identidad de madre. Este contradictorio comportamiento dictado más bien desde afuera, vale decir desde la ideología autoral, conjuga la pulsión de muerte, el sadismo cruel y la maternidad más convencional. Este mismo fenómeno ocurre en el caso de Leonora en Elfin de la historia.

Anita y Violeta las hijas pequeñas de las colaboradoras Lorena y Leonora en El fin de la historia de Heker, son ejes centrales de los quiebres y delaciones a cambio de la seguridad y vida de la hija. En ambas mujeres la identidad de género se presenta transversalmente y traspasa cada una de sus otras identidades y posiciones: la de líder, combatiente, colaboradora, madre, hija y compañera, como también en el 
tránsito inverso que ambas realizan de combatiente a esposa. El deseo de tener poder y reconocimiento se expresa primero en el ascenso en las filas de la dirigencia de la organización revolucionaria y luego en los puestos y autoridad conseguida en los aparatos de inteligencia y represión de la dictadura a través de la delación de compañeros, la "recuperación” de militantes y los servicios prestados a los militares en operaciones de estrategia y propaganda. Por otro lado, la inteligencia y eficiencia son los rasgos que caracterizan el trabajo tanto de Irene como de Leonora en los servicios secretos del régimen, donde se comportan tal como los demás hombres.

Sin embargo, la parte femenina que supuestamente conservan es el deseo de proteger a sus hijas lo que precisamente salva a las colaboradoras de la muerte, ya que antes que militantes son madres y colaboran para salvar y proteger a sus hijas del aparato represivo y sus agentes. Irene después de ver una foto de su pequeña saliendo del colegio reniega del proyecto revolucionario y se convierte en Consuelo Frías, alias "la cubanita", quien delata a sus compañeros combatientes un sin número de veces. Algo similar ocurre con Leonora en El fin de la historia, quien junto con enamorarse de su captor y racionalizar el proyecto represivo de la ESMA (Escuela de Suboficiales de Mecánica de la Armada) y la dictadura, tiene como objetivo verse con su hija, a quien Escualo, su torturador, salvó de la muerte el día del acribillamiento de su esposo Fernando, padre de la niña y dirigente montonero (180). La protección de la hija por parte del torturador, la ropa que le regala (del pañol clandestino con objetos y ropas requisados de presos y allanamientos ilegales) como las visitas de la prisionera a la casa de los abuelos para ver a la niña, son privilegios que le otorga Escualo a cambio de la colaboración. Leonora debe escribir un informe detallado sobre la organización de los montoneros; tarea a la que ella se entrega laboriosamente. Además debido a su conocimiento y entrenamiento de cuadros, Leonora forma y gestiona el "grupo de recuperación" para "salvar" a otros detenidos montoneros y convencerlos que se pasen a las filas del régimen y colaboren con ella y los demás agentes (233 y 235), trabajo que se transforma en una nueva cruzada para ella. La habilidad y meticulosidad con que Leonora dirige a los "recuperados" y cómo colabora con los diversos oficiales de la ESMA (El Halcón, Seisdedos) donde está encarcelada, son la cara contraria de su maternidad y fe en la sacralidad de la vida y en Dios. El pragmatismo y la frialdad se da a la par de la vehemencia por vivir y cumplir sus funciones y nueva misión lo mejor posible (261), todo para poder reunirse con su hija. El deseo de darle una familia y un padre a la pequeña Violeta, se logra de forma definitiva cuando se casa con Escualo (285), sellando el círculo de la tradición y el doble vínculo con su torturador mediante el matrimonio. Esta subjetividad femenina se representa como múltiple y eminentemente contradictoria además de estar sobredeterminada por el afán de reconocimiento. Tanto en el caso de la novela de Liliana Heker como en la de Arturo Fontaine la lógica narrativa se da dentro de una visión maniquea de la sobreviviente/traidora para quien todo es 
transable (amigos, compañeros, esposos), minorizando su victimización y las estrategias de sobrevivencia a las que recurren para salvar a sus hijas y a ellas mismas.

El contraste entre estas dos novelas con los testimonios y autobiografías de sobrevivientes de violencia política y tortura es notable y significativo, en especial si se analizan y comparan desde una perspectiva de género. El texto Putas y guerrilleras. Crímenes sexuales en los centros clandestinos de detención. La perversión de los represores y la controversia en la militancia. Las historias silenciadas. El debate pendiente de Miriam Lewin y Olga Wornat (2014), por ejemplo. denuncia los crímenes sexuales como el subtítulo subraya y la tortura sistemática contra las mujeres militantes que se llevó a cabo en los centros concentracionarios argentinos. Equiparar guerrillera con puta y traidora era la operación discursiva que gatillaba el proceso de humillación y degradación de las prisioneras políticas como advierte Lewin. Para los militares en general y los torturadores en particular, las militantes habían traicionado el orden natural del mundo y la esencia femenina que debía ser vigilada y cautelada dentro del hogar, como esposa, hija y madre. Quienes habían transgredido este régimen de género al participar en política quedaban fuera de la ley, la tradición y la cultura, por lo que dejaban de ser mujeres respetadas para convertirse en "putas" y "traidoras" de la nación y todos sus representantes masculinos. Muchos de los testimonios de las sobrevivientes del centro clandestino El Vesubio, por ejemplo, describen las obscenidades y manoseos a los que eran sometidas mientras sus verdugos las golpeaban o las picaneaban (116). "Las presas eran trofeos de los represores. 'Cuando me pusieron la letra P, pasé a ser parte de la propiedad de Durán Saénz,' dice Elena Alfaro, más de treinta años después (116). Elena confiesa que “el sadismo era violarse mujeres embarazadas" en lo que denomina "el rito bárbaro del coito" y en el que las mujeres servían “nada más.” Agrega que ella sufrió violación sexual teniendo cuatros meses de embarazo y que fue aún más terrible que la de otras mujeres (117). Más aún haber sobrevivido el centro concentracionario le significó una nueva condena social ya que la acusaban de haber sido amante de militares (118).

Para el caso de Chile encontramos descripciones muy semejantes en el testimonio de Nubia Becker Una mujer en Villa Grimaldi (2011), quien pasó por diversos centros clandestinos. Su relato resalta en especial los centros llamados "la venda" tales como La venda de la Calle Londres, la de calle José Domingo Cañas y La Venda Sexy, ${ }^{2}$ conocidas cárceles ilegales donde las militantes sufrían toda suerte de vejaciones sexuales por sus captores. Becker afirma que en estos lugares "la violación era usada como una forma de tortura y amedrentamiento" (76).

2 Ver mi artículo "Memoria y Testimonio Visual en Chile: El documental La Venda de Gloria Camiruaga," Chasqui, Vol. 39 (2) (Nov. 2010): 42-53. Camiruaga realiza el primer trabajo documental en democracia sobre las sobrevivientes. Nueve mujeres relatan sus experiencias de detención ilegal, tortura y violencia sexual en los centros de detención, denunciando la represión dictatorial sobre las presas políticas. 
En comparación con estos testimonios las dos novelas analizadas no solo tergiversan la representación de la militancia y las experiencias de las militantes/sobrevivientes no solo aparece estereotipada y deshistorizada sino condenada a priori. ${ }^{3} \mathrm{El}$ régimen de género en La vida doble y en $\mathrm{El}$ fin de la historia afirma y reproduce el orden patriarcal al punto de naturalizarlo presentando a la militante como una mujer amoral y políticamente condenable, sobredeterminada por su sexo y predisposiciones psíquicas. De este modo, al final las protagonistas son culpables y traidoras a partir de su propia falencia (de género). La historia nacional, los códigos culturales y la política local que las moldean desaparecen casi por completo del discurso literario salvo deformados o esquematizados para ser utilizados como recursos o efectos discursivos. En este contexto ficcional se trata por eso de mujeres desequilibradas, violentas y pragmáticas para quienes el fin justifica los medios. Bajo el cautiverio infernal que experimentan sobreviven a cualquier precio parece ser la conclusión tanto de Fontaine como de Hecker, cuyos narradores claramente las juzgan negativamente. Más aún para Fontaine como lo expresa en una entrevista el mal está enquistado en la traición, falta que define a su protagonista.

La relación entre tortura sexual y consentimiento y la imposibilidad de que haya en circunstancias de terror y asedio libre elección y libre consentimiento me parece un aspecto de vital consideración a la hora de examinar las representaciones ficcionales y testimoniales sobre el pasado militante y sus protagonistas. La crisis radical de estas sujetos como muestran sus diversas identidades forjadas en la sobrevivencia, su conciencia abigarrada y explosionada junto a la multiplicidad de conductas contradictorias, confusas y perversas develan el arrasamiento subjetivo realizado por la maquinaria represiva bajo amenaza, coerción y manipulación constante, vaciando la identidad al punto de borrar lo que estas mujeres fueron en su pasado. En el ámbito literario Carne de perra (2009) de Fátima Sime es tal vez la única novela reciente que privilegia el punto de vista de la sobreviviente militante y lo representa en toda su complejidad y donde, por cierto, aparecen alternativas de retribución y justicia por la violación de los Derechos Humanos no contempladas con anterioridad en el imaginario chileno. ${ }^{4}$ Aquí el

\footnotetext{
${ }^{3}$ A diferencia del éxito editorial y recepción que ha tenido la novela La vida doble, El fin de la historia recibió duras críticas precisamente por la tergiversación de la militancia y la sobrevivencia. Esta notable diferencia en la recepción de ambas novelas probablemente tenga que ver con la historia y el estado de la discusión pública sobre los relatos de la memoria tanto en Chile como en Argentina al momento de la publicación de ambas obras literarias.

${ }^{4}$ La novela Por la patria (1986) de la escritora Diamela Eltit podría considerarse un antecedente literario a Carne de perra, ya que ficcionaliza el testimonio de una sobreviviente llamada Coya dentro de una línea teórica y política similar, aunque en un registro estético distinto. La novela Los vigilantes (1994) de Eltit retoma la relación entre género, política y escritura a través del asedio a una madre cuyo activismo ya no tiene afiliación partidista en una contexto donde el poder ha entrado en otra etapa ya que se ha difuminado y expandido por toda la sociedad para tornarse una dictadura absoluta. Para más información consultar mi libro Passionate Subjects/Split Subjects in Twentieth Century Literature in Chile. Brunet, Bombal and Eltit (2009).
} 
testimonio y la ficción se alían en la textualización de las marcas sexuadas de la violencia política y la memoria traumática de una sobreviviente. 


\section{Bibliografía}

Arfuch, Leonor (2008). Crítica cultural entre política y poética. Buenos Aires: Fondo de Cultura Económica.

Becker Eguiluz, Nubia (2011). Una mujer en Villa Grimaldi. Santiago: Pehuén. (1982, autoeditada como Recuerdos de una mirista bajo el seudónimo Carmen Rojas).

Bergoffen, Debra (2012). Contesting the Politics of Genocidal Rape. Affirming the Dignity of the Vulnerable Body. New Jersey: Routledge.

Fontaine, Arturo (2010). La doble vida. Barcelona: Tusquets.

Fontaine, Arturo (2010b). “La traición es la forma más intensa del mal”. CEP: Santiago de Chile.

Heker, Liliana (1996). El fin de la historia. Buenos Aires: Anagrama.

Jara, René (1982). "Prólogo.” Testimonio y Literatura. Eds. René Jara y Hernán Vidal. Minnesota: Idealogies and Literatures: 1-6.

Lewin, Miriam y Wornat, Olga (2014). Putas y Guerrilleras. Crímenes sexuales en los centros clandestinos de detención. La perversión de los represores y la controversia en la militancia. Las historias silenciadas. El debate pendiente. Buenos Aires: Planeta.

Longoni, Ana (2007). Traiciones. La figura del traidor en los relatos acerca de los sobrevivientes de la represión. Buenos Aires: Grupo Editorial Norma.

Peris, Blanes, Jaume (2013). “Contradicciones de la memoria. Ficcionalización del testimonio y figuración de la traición en La vida doble (Arturo Fontaine, 2010).” Les Atielieres du SAL3 (2013): 49-63.

Sime, Fátima (2009). Carne de perra. Santiago: LOM. 